\title{
THE EFFECTS OF AGE ON MUSCLE TEXTURE AND EATING QUALITIES OF BROILER CHICKENS FOR NIGERIANS
}

\author{
S. A. OFFIONG, I. P. SOLOMON, B. I. UMOH and E. O. EKANEM
}

(Received 30 July 2001; Revision accepted 10 December 2001)

\section{ABSTRACT}

An experiment was conducted to test the effect of age on the eating qualities of broiler chickens slaughtered at $7,8,9,10,11$ and 12 weeks of age for the Nigerian consumers. The birds that provided the meat for the experiment were raised conventionally. Thigh and drumstick meat of the oven-roasted chickens were subjected to a 15-man taste-panel for sensory evaluation, using a rating scale of $1-10$, to score for toughness, flavour, juiciness and general acceptability: like extremely, like moderately, not like or dislike, dislike moderately, dislike extremely. There was no significant difference $(P>0.05)$ in toughness among the 10,11 and 12 weeks old broiler meat. The 8 and 9 weeks old broiler chicken meat were similar and scored significantly higher than the 7 week old chicken meat for toughness. The 7 weeks old broilers scored lowest (not like or dislike). These toughness scores were reflected in the general acceptability scores, where 10,11 and 12 weeks groups were scored extremely liked. The 9 weeks group was also scored extremely liked although less tender in the toughness score. The 7 and 8 weeks old broiler meat were scored liked moderately in general acceptability. Juiciness scores exhibited no significant differences in the panelists' perception among the treatments, whereas in flavour perception the 12 weeks old broiler meat was liked extremely followed by 10 and 11 weeks old broiler meat which were similar and of equal flavour perception and liked moderately. Flavour perception of 7,8 , and 9 weeks old broilers were similar. Age had a profound effect on the meat texture and thus influenced acceptability

Key words: Broiler chickens, age, meat texture, eating qualities.

\section{INTRODUCTION}

The term 'broiler' is applied to birds of the domestic fowl species, which have been bred to grow rapidly and are slaughtered between 7 and 10 weeks of age, depending on the weight of the bird desired. As an article of food, broiler chickens are highly cherished in most cultures because of the tenderness of the meat. However, in the Nigerian culture (and perhaps in other African cultures), the opposite appears to be the case. There is a high preference for meat of older chickens Infact, the older the chicken is. the more preferable the meat is for eating.

In recent times, however, the impact of other cultures appears to be influencing the eating habits of Nigerians. Coupled with this is the establishment of international standard catering services in most Nigerian cities to serve the diverse interests of the fast developing cosmopolitant communities. These catering services make much use of broiler type chicken meat. Nigerians are also developing the habits of "eating out".

In these circumstances, Nigerians seem to be gradually and unconsciously moving towards the acceptance of broiler chickens. However, sometimes the factor of the chicken's age bothers their ego, because in the traditional Nigerian culture, the eating of young chickens is alien. Nigerians have grown to prefer eating older chickens because the meat texture makes it suitable for chewing.

Texture or toughness of meat is influenced by many factors. These include feeding regime (Shrimpton and Miller, 1960); muscle type (Petersen et. al, 1969; Bean and Hansen, 1962); cooking methods (Hostetler and Cover, 1961), and anatomical location of the meat (Salmon et. al, 1981). Petersen et. al, (1959), Shrimpton (1960) and Salmon et. al, (1981), observed that age is the most important single factor influencing meat toughness.

SAMUEL A. OFFIONG, Department of Animal Science, Faculty of Agriculture, , University of Uyo, Uyo, Nigeria ISONGESIT P. SOLOMON, Department of Animal Science, Faculty of . Agriculture, University of Uyo, Uyo, Nigeria BENEDICT I. UMOH, Department of Animal Science, Faculty of , Agriculture, University of Uyo, Uyo, Nigeria ETOK O. EKANEM, Department of Animal Science, Faculty of Agriculture,, University of Uyo, Uyo, Nigeria 
Although Sonaiya and Okeowo (1983) reported that in Nigeria, consumer preference is for broiler chickens older than 8 weeks, these authors did not indicate the age at which this preference is highest. This study was therefore an attempt to determine the age thresh-hold or range at which consumer acceptance of broiler chickens by Nigerians is highest, considering their preference for meat of tough texture.

\section{MATERIALS AND METHOD}

The birds used in this study were Anak straight-run broiler chickens obtained from a local franchise hatchery at day old. Three hundred and sixty (360) of these chickens were initially randomly divided into two similar weight groups such that each group had 180 birds with an average initial body weight of $39 \mathrm{~g} / \mathrm{bird}$. They were placed on floor pens containing wood shavings as litter material. During brooding, the birds were vaccinated intraocularly against Newcastle disease (NCD) and also vaccinated against Infectious Bursal disease (IBD). Each of the groups was fed ad libitum on a common commercial starter diet the composition of which is shown in Table 1. Water was provided ad libitum. At 5 weeks of age, the birds were changed to a finisher diet and maintained on that until the end of the experiment. The composition of the finisher diet is also shown in Table 1. The starter diet contained $2750 \mathrm{kcalME} / \mathrm{kg}$ and $24.5 \%$ crude protein while the finisher diet contained $2850 \mathrm{kcal} / \mathrm{kg}$ and $19.25 \%$ crude protein. Records were kept of feed intake, live body weight and efficiency of feed utilization for each group. The birds were grown to 12 weeks of age.

Then every week, beginning form the $7^{\text {th }}$ week of age, 4 birds per group ( 2 males and 2 females) were randomly removed for sensory evaluation. The birds were starved over-night before being slaughtered by severing the jugular veins.

They were then defeathered, dressed, and placed in polythene bags for refrigeration, until they were required for preparation for sensory
Table 1: Proximate Composition of Starter and Finisher diel. used to grow birds used in the study.

$\begin{array}{llc} & \begin{array}{l}\text { Starter } \\ \text { Diet }\end{array} & \begin{array}{c}\text { Finisher } \\ \text { Diet }\end{array} \\ \text { Moisture \% } & 49.56 & 55.00 \\ \text { Dry Matter \% } & 50.44 & 45.00 \\ \text { Crude Protein \% } & 24.50 & 19.25 \\ \text { Ether Extract \% } & 6.50 & 4.40 \\ \text { Ash \% } & 5.00 & 4.00 \\ \text { Crude Fibre \% } & 4.44 & 4.00 \\ \text { Nitrogen Free Extract \% } & 10.10 & 12.95 \\ \text { M.E. (kcal/kg) } & 2,750.00 & 2,850.00\end{array}$

evaluation by a taste panel. On the day of preparation, the dressed carcasses were removed from the refrigerator and thawed out so that there was no remnant of ice in them. They were washed and left for 30 minutes to drain out before being roasted for 60 minutes at a constant oven-temperature of $170^{\circ} \mathrm{C}$. No salt or other seasoning agent was added during the preparation. Of the oven-roasted meat, the thighs and drumsticks only of each chicken were used. The meat was cut into small but approximately similar sizes using a domestic meat slicer. Each panelist sampled meat from both male and female broilers. A 15-man taste panel was constituted for this purpose. The panelists were asked to sample meat from each treatment (age group) and score them for texture/toughness, flavour, juiciness and general acceptability and record their impression using the following hedonic rating scale: like extremely $(9,10)$, like moderately $(7,8)$, not like or dislike $(5,6)$, dislike moderately $(3,4)$, dislike extremely $(1,2)$. Data collected were subjected to analysis of variance procedure of Snedecor and Cochran (1980). Significance of the difference in treatment means was determined using Duncan's New multiple range test, (Steel and Torie 1960).

\section{RESULTS AND DISCUSSION}

The live performance of the birds used in the study is presented in Table 2. In terms of growth, feed consumption and efficiency of feed utilization, the results showed that the biologic performance of the birds in the experiment in respect of the different parameters were within

Table 2: Biologic performance of the broiler chlickens used in the experiment

\begin{tabular}{|c|c|c|c|c|c|c|c|c|c|c|c|c|}
\hline Age in weeks & 1 & 2 & 3 & 4 & 5 & 6 & 7 & 8 & 9 & 10 & 11 & 12 \\
\hline Mean Body wt. (g) & 85 & 185.7 & 369 & 579 & 800.5 & 1052 & 1350 & 1645 & 1921 & 2210.3 & 2550 & 2765 \\
\hline $\begin{array}{l}\text { Mean Body wt. } \\
\text { gain (g) }\end{array}$ & 46 & 144.7 & 360 & $\varsigma 40$ & 761.5 & 1013 & 1311 & 1606 & 1882 & 2171.3 & 2461 & 2726 \\
\hline Mean Feed intake(y) & 80 & 265 & 280 & 1001 & 1565 & 2234 & 2900 & 3260 & 4710 & 5700 & 6670 & 7796 \\
\hline $\begin{array}{l}\text { Efficiency of Feed } \\
\text { utilization (EVU) }\end{array}$ & 1.7 & 1.8 & 1.6 & 18 & 2.0 & 2.2 & 2.2 & 2.0 & 2.5 & 2.6 & 2.7 & 2.8 \\
\hline
\end{tabular}


Table 3: Mean Panel scores for the eating qualities of broiler chickens slanghtered al 7, 8,9, 10, 11 and 12 weeks of age (scale 110) values in brackets denote standard deviations

\begin{tabular}{|c|c|c|c|c|}
\hline Samples (Ages in weeks) & Toughness & Flavour & Juiciness & General aco \\
\hline 7 & $6.6( \pm 2.2)^{\prime}$ & $7.53( \pm 2.1)^{\prime \prime}$ & $8.9( \pm 1.2)=$ & $7.4(+2.1)^{x}$ \\
\hline 8 & $7.2(+2.1)^{\mathrm{h}}$ & $7.7(+2.0)^{n}$ & $87(+12)$ & $7.9(+2.0)$ \\
\hline 9 & $8.1(+1.2)$ & $7.5(+1.2\}$ & $8.6(+2.1):$ & $9.1(+1.2)^{6}$ \\
\hline 10 & $9.0(+2.0)^{c}$ & $8.7(+2.1)^{6}$ & $1+2.1)$ & $9.4( \pm 1.2)^{6}$ \\
\hline 11 & $9.5( \pm 2.0)^{c}$ & $8.7( \pm 2.1)^{6}$ & $3.5( \pm 2.1) \cdot$ & $9.0(+2.1)^{6}$ \\
\hline 12 & $9.4( \pm 2.0)^{c}$ & $9.6( \pm 2.0)^{c}$ & $( \pm 2.0)^{a}$ & $9.5( \pm 1.1)^{\prime \prime}$ \\
\hline
\end{tabular}

expected performance levels for broiler chickens The significance of these results was to show that these birds, which had grown as expected, were not different from other broiler type chickens in their meat quality characteristics.

The average scores for the organoleptic characteristics are presented in Table $3 . \mathrm{In}$ toughness, the 8 and 9 weeks broiler chicken meat were similar and scored moderately liked $(7,8)$, as against 7 weeks old broiler meat which was significantly different $(P<0.05)$ and scored disliked $(5,6)$ because of tenderness. In flavour and juiciness perceptions, the meat of 7,8 and 9 weeks old broilers were similar and scored moderately liked $(7,8)$. However, in general acceptability, the 7 and 8 weeks old broiler meat were similar and scored moderately liked $(7,8)$, while the 9-week-old meat was scored higher and extremely liked $(9,10)$.

The 10,11 and 12 weeks old broilers were similar in toughness, juiciness and general acceptability and were extremely liked $(9,10)$, indicating higher preference for toughness which reflected in the general acceptability scores. The

weeks old broilers had a more acceptable flavour $(9,10)$ extremely liked, as against the 10 and 11 weeks old broilers, which were only moderately liked $(7,8)$ in this respect. The average panelists' rating scores of $9.0 \pm 2.2$, $9.5 \pm 2.0$ and $9.4 \pm 1.2$ for 10,11 and 12 weeks old broiler chicken meat respectively as against $6.6 \pm$ $\therefore$ and $7.2 \pm 2.1$ in the hedonic rating scale of $1-10$ for eat of 7 and 8 weeks old broilers resper $\quad y$, seem to reflect preference for meat texture it o. ckens older then 9 weeks. This reference as reflected in the general accep ability scores. The 9 weeks old broiler chicke $n$ meat seemed equally accepted in spite of its low rating in toughness score.

- his could be caused by other factors, which mignt bear on the sensory impression of the panelists as they make their final decision on general acceptability. in a similar study on toughness of broiler chicken meat for Nigerians, Sonaiya and Okeowo (1983) observed that toughness increased with age in both male and female broilers, but found no difference in toughness between 12, 14 and 16 weeks old female broilers. There was, however a small but significant difference betwen males of 12 and 14 weeks groups. The authors noted that cooking practices in Nigeria could likely erase such small difference in toughness when such meat is boiled, deep-fatfried and stewed. In the present study, meat from broilers older than 9 weeks were judged more acceptable but we could not determine the age. thresh-hold at which acceptance was optimal.

Although the main focus of the present stucy centered on meat toughness (which is a funt, ion of texture), as it affects the eating quality of bivilers for the Nigerian consumer, vis-a-vis his culturial preference for tough chicken meat, there are other factors which might influence acceptability. Flavour could be one such factor. Flavour has been documented to be of great importance in acceptability of meat and meat products. Apart from the meat of 12 weeks old broilers, which was most acceptable, followed by the meat of 10 and 11 weeks old birds, there were no differences among 7,8 and 9 weeks old broilers in the flavour perception displayed by the panelists. Flavour arises from certain meat components.

Hornstein and Crowe (1960) and Hornstein (1970) observed that lipids are responsible for meat flavour and serve as reservoir for odoriferous fat soluble substances which upon oxidation produce carbonyl compounds that are potent flavour contributors.

Apart from flavour, juiciness is another factor. Brazer (1970) observed that juiciness of cooked meat is that first impression of wetness during the first chews produced by the rapid release of meat fluids. Juiciness is sustained by its slow release and the stimulating effect on salivary flow. This author observed that there is a close correlation between juiciness and fat content of meat-a factor of considerable 
importance in meat flavour.

Although tenderness may determine the acceptability of broiler meat in some cultures, it may not always be the overriding criterion in other cultures. Sometimes, even the distinction between toughness and tenderness may be nebulous and difficult to clearly define. It seems not easy to determine at what point the meat ceases to be tender and becomes tough. From organoleptic stand point, there is a delicate balance between toughness and tenderness and according to Patersen and Lilyblade (1969), no satisfactory explanation of meat tenderness can be made on the basis of specific components of muscle or changes in the specific chemical constituents.

Lawrie (1979), reported that overall impression of tenderness involves three factors: the ease of penetration of the meat by the teeth; the ease with which the meat is crushed and the amount of residue remaining after chewing.

In conclusion, age seems to have a profound effect on muscle texture, rendering it less tender as the broiler chicken grows older, thereby rendering the meat more acceptable to the average Nigerian consumer.

Results in the study have shown how birds older than 9 weeks were rated higher in toughness scores, and were found more acceptable than their counterparts below that age, although in general acceptability no difference was observed between $9,10,11$ and 12 weeks old broilers. Sonaiya and Okoeowo (1983) had similarly observed that toughness increased with age, but they found no difference between 12,14 and 16 weeks old female broilers. The authors, however, reported a small but significant difference in males of 12 and 14 weeks of age, which they believed could be wiped out by cooking methods in Nigeria where the meat is boiled, deep fat-fried and stewed. Lawrie (1979) had observed that although there is no general agreement, the size of the fibres into which the perimysial septa of connective tissues divides the muscle longitudinally is believed to affect muscle texture and the tenderness. The author observed that apart from age, postmortem glycolysis may also affect muscle texture and so influence the eating quality, and by implication the acceptability of the meat.

\section{ACKNOWLEDGEMENT}

Funds for this study were provided from the University Research Grant, for which the authors are grateful. The services provided by the technical staff of the Poultry Unit. Teaching and Research Farm, University of Uyo, in the routine management of the birds are also acknowledged. The services of the Catering Department of the University Guest House in the preparation of the meat for the taste panel are also acknowledge.

\section{REFERENCES}

Bean, M.L. and Henson, H. L. 1992. The Utilization of geese: Tendemess and yield. Poultry Sc. 41:236 242.

Bratzer, L. J. 1970. Palatahility Factors and evaluation In:The Science of Meat and meat Products. $2^{\text {nd }} \mathrm{Ed}$. W. H. Freeman and Co. San Francisco, Publisher.

Hostetler, R. L. and Cover, S. 1961 Relationship of extensibility of muscle fibres to tenderness of beef. J. Food Sci. 26:535-540.

Hornstein 1. 1970 Chemistry of Meat flavour. In: The Science of Meat and Meat Products. $2^{\text {nd }}$ Ed. W.H. Freeman and Co. San Francisco. Publisher.

Hornstein 1. and Crowe, P. F., 1960. Flavour Studies on Beef and Pork. J. Ag. Food Chem. 8: 494.

Lawrie, R. A. 1979. Meat Sci. $3^{\text {rd }}$ Ed. Pergamon Press. Oxford and New York. of breast muscle in nomal and two dystrophic mutant strain of chickens. Journ, Food Sci. 74:142-145.

Petersen, D. W. Simone, M. Lilyblade A. L. and Martin, R. 1959. Some factors affecting intensity of flavour and toughness of chicken muscle. Food Tech 13:204 211.

Salmon, R. E., Gardiner E. E. Klein K. K. and Larmond E. 1981. Effect of Canola (low glucosinclate rapeseed) meal protein and nutrient density on performance, carcass grade and meat yield and of canola meal on sensory quality of broilers. Poultry Sci. $60: 2519$ 2528.

Snedecor, G. W, and Cochran, W. G. 1980 Statistical Methods $7^{\text {th }}$ Ed. Ames lowa. lowa State Univ. Press. 265-268.

Sonaiya, E. B., and Okeowo O. O. 1983. Live performance, abdominal fat ant toughness of $6-16$ weck old broilers. 1. Anim, Prod. Res. 3 (2): 103 - 114.

Shrimpton, D. H. and Miller W. S. 1960. Some causes of toughness in broilers. Effects of breed, management and sex. Br. Poultry Sc. i:111-118.

Shrimpton, D. H., 1960. Some causes of toughness in broilers. Packing station procedure. Its influence on the chemical changes associated with rigor mortis and on tenderness of the flesh. Poultry Sc. 37:1028 -1033 .

Steel, R. G. D. and Torrie, J. M.. 1960. Principles and Procedure of Statistics. Mc Graw - Hill Book Company. New York 